\title{
Proximity of food retailers to schools and rates of overweight ninth grade students: an ecological study in California
}

\author{
Philip H Howard ${ }^{1 *}$, Margaret Fitzpatrick', Brian Fulfrost ${ }^{2}$
}

\begin{abstract}
Background: The prevalence of obesity and overweight in youth has increased dramatically since the 1980s, and some researchers hypothesize that increased consumption of low-nutrient, energy-dense foods is a key contributor. The potential importance of food retailers near schools has received increasing attention, but public health research and policy has focused primarily on fast food restaurants. Less is known about the relationship between overweight/obesity and other types of retailers. This study aims to investigate the potential associations between nearby 1) fast food restaurants, 2) convenience stores, and 3) supermarkets, and rates of overweight students in California schools.
\end{abstract}

Methods: We examined the rate of overweight ninth grade students in public schools in 2007 using linear regression. The percentage of overweight students per school was determined by a state required physical fitness test, with three different options for measuring individual body composition. Our key independent variables were the presence of three different types of retailers within $800 \mathrm{~m}$ network buffers of the schools. Additional independent variables included school ethnic, gender and socioeconomic composition, as well as urban/non-urban location. We obtained the data from the California Department of Education and ESRI, Inc.

Results: The presence of a convenience store within a 10-minute walking distance of a school was associated with a higher rate of overweight students than schools without nearby convenience stores, after controlling for all school-level variables in the regression (1.2\%, $95 \%$ confidence interval $0.03,2.36)$. Nearby fast food restaurants and supermarkets, however, were not associated with school rates of overweight students.

Conclusions: Public health researchers and policy-makers interested in the food environments outside schools should expand their recent focus on nearby fast food restaurants to include convenience stores, which may also be important sources of low-nutrient, energy-dense foods for students.

\section{Background}

The rate of child and adolescent obesity in the United States has increased threefold since 1980, and although currently steady, remains at $17 \%$ [1]. Excess weight in children and young adults is associated with greater risks for diabetes, cardiovascular disease and certain cancers [2], as well as associated economic costs [3]. A number of studies have implicated increased consumption of low-nutrient, energy-dense foods such as

\footnotetext{
* Correspondence: howardp@msu.edu

'Department of Community, Agriculture, Recreation and Resource Studies, Michigan State University, 316 Natural Resources, East Lansing, MI, 48824, USA

Full list of author information is available at the end of the article
}

sugary drinks and fast foods as a factor in elevated rates of overweight and obesity [4-7].

Recently, both researchers and policy-makers have increased their attention on the role of retailers in providing access to these foods as a potential risk factor for increased body fat [8]. Although our understanding of these potential relationships remains limited, several studies focusing on children and young adults in the US have reported associations between food environments and weight status. Residing near fast food restaurants [9] and convenience stores, for example [10,11], is associated with excess weight, while residing near supermarkets is associated with lower weight $[11,12]$. While not all studies have observed these types of associations 
[12-15], similar relationships have been reported for the majority of studies involving adults [16-20]. It is hypothesized that the increased availability of lowenergy, nutrient-dense foods in supermarkets (e.g. fresh fruits and vegetables) may account for the most typical differences observed among retailer types [18,21].

Other important contexts for children and young adults are the food environments inside and just outside schools, where students may consume up to half of their total food intake [22]. There have been relatively few studies of food environments outside of schools with respect to the outcomes of overweight or obesity, and, as with studies involving adults, more have focused on fast food restaurants than other types of retailers [23]. A statewide study of middle and high school students in California reported a $6 \%$ increase in the odds of overweight when attending schools within $800 \mathrm{~m}$ of fast food restaurants, as well as increased soda consumption [24]. An ecological study, also conducted in California, reported higher school rates of overweight when fast food restaurants were located within a smaller, .1 mile buffer, after controlling for school-level variables [25]. One of the few studies of multiple types of retailers near schools in the United States found no associations between proximity to fast food restaurants or convenience stores and adolescent overweight in Minnesota, but these variables were associated with increased consumption of sugar-sweetened beverages [26].

The plausibility of convenience stores near schools influencing dietary patterns in children and young adults is strengthened by a recent observational study in Philadelphia: the researchers reported that fourth, fifth and sixth grade students frequently shopped at corner stores before and after school, and were most likely to buy inexpensive sugar-sweetened drinks, chips and candy (averaging approximately $350 \mathrm{kcal}$ per purchase) [27]. We therefore examined associations between the proximity of fast food restaurants, convenience stores and supermarkets to schools in California, and school overweight rates. We hypothesized that 1 ) proximity to fast food restaurants would be associated with higher school overweight rates, 2) proximity to convenience stores would be associated with higher school overweight rates, and 3) proximity to supermarkets would be associated with lower school overweight rates.

\section{Methods}

\section{Variables and Data Sources}

The dependent variable for this study was the rate of overweight ninth grade students for public schools in California in 2007. The data were obtained from California Department of Education, which administers a physical fitness test (FITNESSGRAM ${ }^{\circledR}$ ) between February and May of each year. The test is required by state law for public school students in $5^{\text {th }}, 7^{\text {th }}$ and ninth grade, and in 2007 approximately $90 \%$ of schools participated [28]. The test reports students' body composition, as measured by skinfold (preferred method), body mass index (weight in kilograms divided by height in meters squared), or bioelectric impedance analyzers. These three different measurement options are provided to ensure broad participation, and while all are subject to error (typically 3 to $6 \%$ ), comparisons of different methods report high test-retest reliability $[29,30]$. The definition of overweight differs slightly from others, such as the Centers for Disease Control. Instead, classification in this category is determined by criterion-referenced gender-, age- and test-specific cut-offs (e.g. skinfold $<32$ for a 15 year old female; body mass index $<24.5$ for a 14 year old male). These standards were established by a national advisory panel, convened by the Cooper Institute of Dallas, Texas [29].

Our analysis is at the school-level because the physical fitness test results are publicly available only at this level of aggregation-individual results are confidential. The original dataset included all public schools in California that reported physical fitness test results. To obtain more stable rates of overweight students, we excluded schools with less than 100 students from the analysis. We focused on ninth graders because they are expected to have greater mobility, and greater financial ability to purchase food from nearby retailers, when compared to $7^{\text {th }}$ and $5^{\text {th }}$ graders.

The physical fitness dataset also provided information on the gender and ethnic composition of students tested in each school. We used this information to construct a variable for gender composition, with percentage of male students as the reference category. We also constructed variables for student composition by major ethnic groups, with percentage non-Hispanic white as the reference category, and additional variables for the percentage of students that were Hispanic/Latino, AfricanAmerican, Asian, Native American (including Alaskan native), Pacific Islander, and those who declined to state their ethnicity.

The California Department of Education was the source for several additional datasets, all of which are also publicly available. One contained the street addresses of schools in the study, which we used in constructing the retailer proximity variables described below. We obtained two other datasets to construct independent variables for 1) percentage of all students (not just ninth graders) in each school receiving free \& reduced price meals in 2007, and 2) urban or non-urban school location. The subsidized meal variable was used as a proxy for school-level socioeconomic status, which at the individual-level is known to be strongly associated with overweight. We defined urban schools as those 
located in large or mid-size cities (based on U.S. Census Bureau classifications) and compared them to schools that were not in these areas, defined as non-urban.

Another publicly available dataset was purchased from Environmental Systems Research Institute, Inc. (ESRI), It was used to construct variables for the presence/ absence of three classes of retailers near schools: 1) fast food restaurants, 2) convenience stores, and 3) supermarkets. ESRI provided geocoded information for data that was first collected by the marketing firm InfoUSA, in 2007. We then selected retailers based initially on the following 8-digit National American Industry Classification System (NAICS) codes: Limited Service Restaurants (72221105), Convenience Stores (44512001), Supermarkets and Grocery Stores (44511001). As reported in another study however [31], the NAICS codes were inconsistently applied. For instance, there were many recognizable convenience stores identified with the NAICS code for Grocer Retail (44511003). To reduce misclassification, retail locations in this category that contained the terms 'Quick-,' 'Mini-,' and 'Liquor-' in the company name were recoded into the "convenience stores" category $(n=668)$. Supermarkets were defined as retailers in the Supermarket and Grocery Stores category with $\$ 2$ million or more in annual sales, based on the Food Marketing Institute's definition [32]. Because Limited Service Restaurants (72221105) was also an overly broad category, those with five or more locations were selected as "fast food restaurants," or business chains that provide low price meals without table service. This category included all of the major fast food chains (e.g. McDonald's, Burger King, Taco Bell, Domino's). For the entire state of California we identified 3,646 supermarkets, 4,069 convenience stores, and 20,668 fast food restaurants.

\section{GIS analysis}

The point locations of the schools were geocoded with the Streetmap USA (2006) dataset provided by ESRI, based on street addresses. We validated the accuracy of geocoded locations by spot-checking $10 \%$ of the schools. We found the addresses of these schools through web searches and re-geocoded them using Mapquest, an online geocoding service owned by America Online, Inc. [33]. Our spot-checking indicated more than $99 \%$ accuracy in our geocoded school locations.

Most previous studies of food proximity have not incorporated the actual pedestrian walking network into their analyses of proximity or food access. Instead they rely on Euclidean (straight-line, circular radius) buffers that do not account for the street network, sidewalks, and other elements of the areas surrounding schools where walking is most feasible $[24,31,34,35]$. The result is that the area covered by Euclidean buffers can be substantially more than the area covered by equivalent distance network buffers. This can lead to erroneous or misleading results. To improve accuracy in this study we utilized network buffers along the actual street network for the entire state of California.

We used ESRI's Network Analyst extension to ArcView 9.1 to create $800 \mathrm{~m}$ network buffers around the final geocoded school points. This distance was selected because it is approximately a ten-minute walk, and is commonly used in other studies of retail food access near schools $[24,31,35,36]$. These network buffers included both the street lines making up the $800 \mathrm{~m}$ street networks around each school, as well as polygons that contained the area encompassing these networked buffers. Once the network buffers were created, we performed a spatial join to calculate the number of fast food, convenience and supermarket retailers located within each of these network buffers. The final result of our GIS analysis was a matrix denoting the presence or absence of each of three classes of retailers within $800 \mathrm{~m}$ along the street network for each school. These data were exported out of the GIS for statistical analysis.

\section{Statistical analysis}

We analyzed all data with SPSS (version 15.0.1). Our analysis included descriptive statistics, correlations (Kendall's tau-b), and linear regression. Our first model regressed the dependent variable of school rate of overweight ninth grade students on the three types of nearby retailers assessed in the GIS analysis. Our second model included the additional school-level variables (ethnic, socioeconomic and gender composition, and urban/nonurban location) for comparison.

Prior to regression, we applied logarithm transformations to school ethnic composition variables, with the exceptions of the two largest groups (Hispanic/Latino and White, non-Hispanic), in order to meet assumptions of normality. We also employed multiple imputation as a strategy for dealing with missing data for two independent variables: percentage of students receiving free \& reduced price meals, and urban/non-urban school location. This involved utilizing information from the existing data to generate plausible values for missing data, while also representing uncertainty by generating five different data sets with imputed values. These values were imputed with the software Amelia II (version 1.2), and combined for analysis using the procedures detailed by King et al. [37]

\section{Results}

\section{Descriptive statistics}

Table 1 shows the descriptive characteristics of the study. The sample consisted of 879 public schools in California with scores for 100 or more ninth grade 


\begin{tabular}{|c|c|c|c|c|c|}
\hline & Percentage & Mean (SD) & Min & Max & Percentage Missing Prior to Imputation \\
\hline \multicolumn{6}{|l|}{ Dichotomous variables } \\
\hline \multicolumn{6}{|l|}{ Retailers $^{\mathrm{a}}$} \\
\hline Fast Food & 50.4 & & & & \\
\hline Convenience & 28.6 & & & & \\
\hline Supermarket & 23.8 & & & & \\
\hline \multicolumn{6}{|l|}{ School location } \\
\hline Non-urban & 52.6 & & & & \\
\hline Urban & 38.7 & & & & \\
\hline \multicolumn{6}{|l|}{ Continuous variables } \\
\hline Number of students per school & & $474.2(229.6)$ & 100 & 1486 & 0 \\
\hline$\%$ Overweight & & $30.7(10.4)$ & 3.0 & 75.4 & 0 \\
\hline$\%$ Male & & $50.9(4.5)$ & 26.6 & 81.0 & 0 \\
\hline$\%$ Female & & $49.1(4.5)$ & 19.0 & 73.4 & 0 \\
\hline$\%$ White, non-Hispanic & & $32.8(25.6)$ & 0 & 91.4 & 0 \\
\hline \% Hispanic/Latino & & $45.2(27.3)$ & 1.6 & 100.0 & 0 \\
\hline$\%$ African-American & & $7.3(9.4)$ & 0 & 79.0 & 0 \\
\hline$\%$ Asian & & $12.0(14.8)$ & 0 & 86.8 & 0 \\
\hline$\%$ Native American & & $0.84(1.4)$ & 0 & 14.9 & 0 \\
\hline \% Pacific Islander & & $0.7(1.0)$ & 0 & 8.6 & 0 \\
\hline$\%$ Declined to state ethnicity & & $1.5(3.0)$ & 0 & 45.7 & 0 \\
\hline$\%$ Free/reduced meals & & $42.1(26.0)$ & 0 & 100.0 & 6.4 \\
\hline
\end{tabular}

${ }^{\mathrm{a}}$ At least one such retailer within an $800 \mathrm{~m}$ network buffer.

students on the California Physical Fitness Test in 2007 (659 schools reporting scores for fewer ninth grade students were excluded from the analysis; 479 of these excluded schools reported overweight scores, with a mean rate of $33.8 \%$ ). The number of students per school ranged from 100 to 1486 . The percentage of students that were overweight in each school ranged from 3.0 to $75.4 \%$, with a mean of $30.7 \%$. Although this is a substantial range, it is not surprising given the heterogeneity in ethnic and income and composition of these schools (e.g. up to $91.4 \%$ white, non-Hispanic, or $100 \%$ Hispanic/Latino). Half of the study schools were located within an $800 \mathrm{~m}$ network buffer of a fast food restaurant. The other two types of retailers examined were less prevalent, with $28.6 \%$ of schools located near convenience stores, and $23.8 \%$ near supermarkets.

\section{Correlations}

Rates of overweight ninth grade students were positively associated with the presence of nearby convenience stores and fast food restaurants, as shown in Table 2. Convenience stores demonstrated stronger correlations with school overweight rates (.138) than fast food restaurants (.091). Supermarkets demonstrated no association with school overweight rates, however.

Schools with higher percentages of Latino students were more likely to be near convenience stores (.137) and fast food restaurants (.101), but were not more likely to be near supermarkets (.020). Schools with more low-income students, as measured by the percentage receiving free \& reduced price meals, demonstrated very similar correlations (.131 with convenience stores, .108 with fast food, .003 with supermarkets). Schools located in non-urban areas were less likely to be near fast food restaurants (-.137) and had lower rates of overweight students (-.083) when compared to urban schools.

\section{Regression}

The first model regresses the percentage of overweight ninth grade students on the three retail variables, as shown in Table 3. It indicates that controlling for the influence of these retailers simultaneously, the presence of a convenience store within an $800 \mathrm{~m}$ network buffer of a school is predicted to increase the percentage of overweight students by $3.5 \%$ (95\% confidence interval $1.9,5.2)$. For a typical-sized school ( 474 ninth grade students), for example, approximately 17 additional students in this grade would be expected to fall in the overweight category in comparison to school without a nearby convenience store. The presence of a fast food restaurant within this same distance is predicted to increase the percentage of overweight students by $1.8 \%$ (95\% confidence interval $0.2,3.4$ ), approximately half the strength of the convenience store association. The presence of a supermarket within this buffer is predicted to 
Table 2 Correlations (Kendall's tau-b) for key school variables in the analysis $(\mathbf{n}=\mathbf{8 7 9})$

\begin{tabular}{|c|c|c|c|c|}
\hline & Overweight (school \%) & Fast Food ${ }^{a}$ & Convenience $^{a}$ & Supermarket $^{\mathrm{a}}$ \\
\hline Fast Food ${ }^{a}$ & $.091^{* *}$ & & & \\
\hline Convenience $^{a}$ & $.138^{* *}$ & $.337^{* *}$ & & \\
\hline Supermarket ${ }^{a}$ & -.001 & $.426^{* *}$ & .231 & \\
\hline Number of Students & -.013 & .038 & -.028 & -.016 \\
\hline$\%$ Female & .020 & -.019 & .007 & -.019 \\
\hline \% Hispanic/Latino & $.494^{* *}$ & $.101^{* *}$ & $.137^{* *}$ & .020 \\
\hline$\%$ African-American (log) & $.161^{* *}$ & $.072^{* *}$ & .008 & -.032 \\
\hline \% Asian (log) & $-.233^{* *}$ & .016 & $-.082^{* *}$ & .002 \\
\hline$\%$ Native American (log) & $-.112^{* *}$ & $-.100^{* *}$ & $-.060^{*}$ & -.051 \\
\hline \% Pacific Islander (log) & $-.055^{*}$ & .039 & -.065 & -.043 \\
\hline$\%$ Declined to state (log) & $-.162^{* *}$ & -.043 & $-.059^{*}$ & .030 \\
\hline$\%$ Free/reduced meals & $.494^{* *}$ & $.108^{* *}$ & $.131^{* *}$ & .003 \\
\hline Non-urban location & $-.083^{* *}$ & $-.137^{* *}$ & -.057 & -.058 \\
\hline
\end{tabular}

*p $<.05,{ }^{* *} p<.01$

a At least one such retailer within an $800 \mathrm{~m}$ network buffer.

decrease the number of overweight students by $1.9 \%$ (95\% confidence interval $-3.6,-0.1$ ). The model itself explains $3 \%$ of the variation in rates of overweight students.

The second regression model is shown in Table 4. This model includes additional school-level variables that are known to be associated with overweight status. The variation explained was $51 \%$, a substantial increase when compared to the first model. After controlling for these additional variables, the associations between retailers and school overweight rates were weaker, and only the association with convenience stores remained. The presence of a convenience store near a school is predicted to increase its overweight rate by $1.2 \%$. This is approximately $1 / 3$ of that reported in model 1 , but the $95 \%$ confidence interval $(0.03,2.4)$ continues to indicate a positive relationship. For a school with the mean number of ninth graders (474), the model predicts that an additional 6 students would be overweight in comparison to a school without a nearby convenience store. The associations with fast food restaurants and supermarkets when controlling for additional variables are much smaller, and their 95\% confidence intervals include zero.

Table 3 Regression of school percentage of overweight ninth grade students on nearby retailers

\begin{tabular}{lrrrr}
\hline & $\mathbf{B}$ & $\mathbf{9 5 \%} \mathbf{C l}$ & $\boldsymbol{\beta}$ & $\mathbf{S E}$ \\
\hline (Constant) & 29.19 & $(27.20,30.17)$ & & 0.50 \\
Fast Food $^{\mathrm{a}}$ & 1.80 & $(0.24,3.35)$ & 0.09 & 0.79 \\
Convenience $^{\mathrm{a}}$ & 3.54 & $(1.94,5.14)$ & 0.15 & 0.81 \\
Supermarket $^{\mathrm{a}}$ & -1.86 & $(-3.62,-0.09)$ & -0.08 & 0.90 \\
& & & & \\
F & 10.60 & & & \\
Adjusted R-squared & 0.03 & & & \\
\hline
\end{tabular}

${ }^{a}$ At least one such retailer within an $800 \mathrm{~m}$ network buffer.
Variables that had stronger positive associations with school overweight rates than nearby convenience stores included the percentage of students receiving free or reduced price meals, and percentage of Latino, African-American and Native American students. The percentage of Asian-American students demonstrated a stronger negative association with obesity rates. Variables in the model that were more weakly associated with school overweight rates than nearby convenience stores included gender composition, percent Pacific Islander or "declined to state" ethnicity, and urban/non-urban location.

Table 4 Regression of school percentage of overweight ninth grade students on nearby retailers, including additional school-level variables

\begin{tabular}{lrrrr}
\hline & $\mathbf{B}$ & $\mathbf{( 9 5 \%} \mathbf{C l})$ & $\boldsymbol{\beta}$ & $\mathbf{S E}$ \\
\hline (Constant) & 15.70 & $(8.88,22.32)$ & & 3.42 \\
Fast Food $^{\mathrm{a}}$ & -0.04 & $(-1.18,1.10)$ & -0.01 & 0.58 \\
Convenience $^{\mathrm{a}}$ & 1.20 & $(0.03,2.36)$ & 0.05 & 0.59 \\
Supermarket $^{\mathrm{a}}$ & -0.33 & $(-1.61,0.95)$ & -0.01 & 0.65 \\
\% Female & -0.03 & $(-0.14,0.08)$ & -0.01 & 0.05 \\
\% Hispanic/Latino & 16.17 & $(12.83,19.51)$ & 0.43 & 1.70 \\
\% African-American (log) & 5.81 & $(4.45,7.16)$ & 0.23 & 0.69 \\
\% Asian (log) & -1.84 & $(-3.22,-0.46)$ & -0.08 & 0.70 \\
\% Native American (log) & 4.61 & $(1.81,7.41)$ & 0.09 & 1.43 \\
\% Pacific Islander (log) & 0.96 & $(-2.18,4.09)$ & 0.02 & 1.60 \\
\% Declined to state ethnicity (log) & 1.53 & $(-0.63,3.69)$ & 0.04 & 1.10 \\
\% Free/reduced meals & 11.08 & $(7.48,14.68)$ & 0.28 & 1.83 \\
Non-urban location & 0.34 & $(-0.79,1.46)$ & 0.02 & 0.57 \\
& & & & \\
F & 75.89 & & & \\
Adjusted R-squared & 0.51 & & & \\
\hline
\end{tabular}

${ }^{a}$ At least one such retailer within an $800 \mathrm{~m}$ network buffer. 


\section{Discussion}

This study indicated that schools within $800 \mathrm{~m}$ of convenience stores had higher rates of overweight students than schools located farther from these retailers. This association was independent of ethnic, socioeconomic and gender composition, as well as urban/non-urban location. It extends similar findings reported in two studies of children that focused on a different context, retailers surrounding homes. One involved $8^{\text {th }}$ and $10^{\text {th }}$ grade students nationally, [11] and the other focused on 6-8 year old children in East Harlem, NY [10], but both reported that residing near convenience stores was associated with a higher body mass index.

Our analysis also underscores the importance of socioeconomic variables on the risks of being overweight. We observed that 1) the percentage of Hispanic/Latino students, 2) the percentage of students receiving free \& reduced price meals, and 3) the percentage of AfricanAmerican students, demonstrated much stronger associations with school overweight rates than the other variables that we tested. Importantly, the first two of these variables were associated with an increased likelihood that a school would be located near a convenience store. While inequalities in retail food environments outside of schools were not a focus of this study, the results provide further support for income and ethnic disparities reported by others $[31,34,35,38]$. The potential risks of having convenience stores near schools, even if substantially smaller than known individual/ household-level risks by comparison, are nonetheless disproportionately borne by those already at much higher risk of being overweight.

While two recent studies found that residing near supermarkets was associated with a lower risk of overweight, [11,12] our study of the environments surrounding schools did not find an association between the proximity of these retailers and rates of student overweight. Also, in contrast to two previous studies in California [24,25], we failed to find a consistent association between school overweight rates and nearby fast food restaurants. Our results therefore provide only partial support for theories that the availability of low-energy, nutrient-dense foods and/or low-nutrient, energy-dense foods contributes to differing consumption patterns and weight outcomes in students. Some of the limitations of our approach, described below, may account for why these expected associations were not observed, however.

\section{Study limitations}

Our study has a number of limitations. Its ecological design limits inferences about school food environments' potential relationships with individual-level behaviors/ outcomes. Even at the school-level we lacked data for variables known to influence food/beverage consumption and physical activity, such as the type of food service [39], presence or absence of vending machines [40], open/closed campus [31], mode of transportation (e.g. buses), and physical education requirements [41]. In addition, the cross-sectional design did not allow for analysis of the time order of exposures and the outcome. Another potential limitation was the exclusion of schools with small numbers of students due to unstable rates. Our sources of data are prone to error, such as those we utilized to classify and geographically locate the retailers, as well as the methods and standards used to determine student overweight status. This error may bias the estimates toward or away from the null hypothesis.

\section{Study strengths}

Our study also has several strengths. We utilized network buffers to more accurately model retailer distance to schools when compared to studies that have employed Euclidean buffers. We simultaneously examined associations between three different retail types and the outcome of overweight, rather than focusing on a single type of retailer. Finally, our outcome measure of student overweight, although aggregated at the schoollevel, was based on criterion-referenced, test-specific measurements, instead of less accurate student selfreported height and weight.

\section{Suggestions for future research}

Future studies could address some of the limitations of our analysis by ground-truthing retail location data, as well as incorporating additional school-level variables that may influence student energy intake and expenditure. Subsequent efforts could also benefit from characterizing the quantity and types of foods available within restaurants and stores, rather than relying on retailer categories, as otherwise similar establishments may differ greatly in their availability of healthy and less healthy foods $[42,43]$. Additional methodological improvements could include longitudinal designs and/or cross-classified multilevel models [44]. The latter could incorporate the retail food environments of both schools and residences at the macro-level, and examine how these interact with individual student health outcomes and behaviors, as in a recent study conducted by Laska et al. with adolescents in Minneapolis/St. Paul [26].

\section{Conclusions}

This ecological study in California found that nearby convenience stores were associated with higher school rates of overweight students, after controlling for socioeconomic and ethnic factors known to be linked to this 
outcome. Contrary to our expectations, we did not find strong support for an association between nearby fast food restaurants and higher school rates of overweight students, nor for an association between nearby supermarkets and lower rates of overweight students. The limitations of our study suggest that these findings should be interpreted with caution. They do indicate, however, that public health researchers and policymakers interested in the food environments outside schools should expand their recent focus on nearby fast food restaurants to include convenience stores, as these may also be important sources of low-nutrient, energydense foods for students.

\section{Acknowledgements}

Funding for the study was provided by Michigan State University. The authors wish to thank Dylan W. Loudon for assistance with the GIS analysis, and the reviewers for their helpful suggestions.

\section{Author details}

'Department of Community, Agriculture, Recreation and Resource Studies, Michigan State University, 316 Natural Resources, East Lansing, MI, 48824, USA. ${ }^{2}$ Design, Community \& Environment, 1625 Shattuck Ave, Suite 300, Berkeley, CA, 94709, USA.

\section{Authors' contributions}

$\mathrm{PHH}$ conceived of and designed the study, participated in its coordination and drafted the manuscript. MF conducted data preparation and statistical analysis, and assisted with drafting the manuscript. BF conducted the GIS analysis and assisted with drafting the manuscript. All authors read and approved the final manuscript.

\section{Competing interests}

The authors declare that they have no competing interests.

Received: 13 July 2010 Accepted: 31 January 2011

Published: 31 January 2011

\section{References}

1. Ogden $C L$, Carroll MD, Curtin LR, Lamb MM, Flegal KM: Prevalence of high body mass index in US children and adolescents, 2007-2008. JAMA 2010, 303:242-249.

2. Ogden $\mathrm{CL}$, Yanovski SZ, Carroll MD, Flegal KM: The epidemiology of obesity. Gastroenterology 2007, 132:2087-2102.

3. Cawley J: The economics of childhood obesity. Health Aff (Millwood) 2010, 29:364-371.

4. Babey SH, Jones M, Yu H, Goldstein H: Los Angeles: UCLA Center for Health Policy Research; 2009.

5. Gibson S: Sugar-sweetened soft drinks and obesity: a systematic review of the evidence from observational studies and interventions. Nutr Res Rev 2008, 21:134-147.

6. Malik VS, Schulze MB, Hu FB: Intake of sugar-sweetened beverages and weight gain: a systematic review. Am J Clin Nutr 2006, 84:274-288.

7. Rosenheck R: Fast food consumption and increased caloric intake: a systematic review of a trajectory towards weight gain and obesity risk. Obes Rev 2008, 9:535-547.

8. Larson N, Story M: A review of environmental influences on food choices. Ann Behav Med 2009, 38(Suppl 1):S56-73.

9. Mellor JM, Dolan CB, Rapoport RB: Child body mass index, obesity, and proximity to fast food restaurants. Int J Pediatr Obes 2010, 6:60-68.

10. Galvez MP, Hong L, Choi E, Liao L, Godbold J, Brenner B: Childhood obesity and neighborhood food-store availability in an inner-city community. Acad Pediatr 2009, 9:339-343.

11. Powell LM, Auld MC, Chaloupka FJ, O'Malley PM, Johnston LD: Associations between access to food stores and adolescent body mass index. Am J Prev Med 2007, 33:S301-7.
12. Liu GC, Wilson JS, Qi R, Ying J: Green neighborhoods, food retail and childhood overweight: differences by population density. Am J Health Promot 2007, 21:317-325.

13. Burdette HL, Whitaker RC: Neighborhood playgrounds, fast food restaurants, and crime: relationships to overweight in low-income preschool children. Prev Med 2004, 38:57-63.

14. Crawford DA, Timperio AF, Salmon JA, Baur L, Giles-Corti B, Roberts RJ, Jackson ML, Andrianopoulos N, Ball K: Neighbourhood fast food outlets and obesity in children and adults: the CLAN Study. Int I Pediatr Obes 2008, 3:249-256.

15. Sturm R, Datar A: Body mass index in elementary school children, metropolitan area food prices and food outlet density. Public Health 2005, 119:1059-1068.

16. Fleischhacker SE, Evenson KR, Rodriguez DA, Ammerman AS: A systematic review of fast food access studies. Obes Rev.

17. Larson NI, Story MT, Nelson MC: Neighborhood environments: disparities in access to healthy foods in the U.S. Am J Prev Med 2009, 36:74-81.

18. Morland K, Diez Roux AV, Wing S: Supermarkets, other food stores, and obesity: the atherosclerosis risk in communities study. Am J Prev Med 2006, 30:333-339.

19. Morland KB, Evenson KR: Obesity prevalence and the local food environment. Health Place 2009, 15:491-495.

20. Spence JC, Cutumisu N, Edwards J, Raine KD, Smoyer-Tomic K: Relation between local food environments and obesity among adults. BMC Public Health 2009, 9:192.

21. Bodor JN, Ulmer VM, Dunaway LF, Farley TA, Rose D: The rationale behind small food store interventions in low-income urban neighborhoods: insights from New Orleans. J Nutr 2010, 140:1185-1188.

22. Story M, Nanney MS, Schwartz MB: Schools and obesity prevention: creating school environments and policies to promote healthy eating and physical activity. Milbank Q 2009, 87:71-100.

23. Holsten JE: Obesity and the community food environment: a systematic review. Public Health Nutr 2009, 12:397-405.

24. Davis B, Carpenter C: Proximity of fast-food restaurants to schools and adolescent obesity. Am J Public Health 2009, 99:505-510.

25. Currie J, DellaVigna S, Moretti E, Pathania V: The Effect of Fast Food Restaurants on Obesity and Weight Gain. Am Econ J: Econ Policy 2010, 2:32-63.

26. Laska MN, Hearst MO, Forsyth A, Pasch KE, Lytle L: Neighbourhood food environments: are they associated with adolescent dietary intake, food purchases and weight status? Public Health Nutr 2010, 1-7.

27. Borradaile KE, Sherman S, Vander Veur SS, McCoy T, Sandoval B, Nachmani J, Karpyn A, Foster GD: Snacking in children: the role of urban corner stores. Pediatrics 2009, 124:1293-1298.

28. Education CDo: 2007 California Physical Fitness Test. 2007, 1-7.

29. Welk GJ, Meredith MD, (Eds): FITNESSGRAM/ACTIITYGRAM Reference Guide Dallas: Cooper Institute; 2008.

30. M I, GJ W, J M, J S: The reliability and convergent validity of field tests of body composition in young adolescents. J Phys Act Health 2006, 3 : S67-S77.

31. Sturm R: Disparities in the food environment surrounding US middle and high schools. Public Health 2008, 122:681-690.

32. Supermarket Facts: Industry Overview. [http://www.fmi.org/facts_figs/ superfact.htm]

33. D R, HA K: Comparative evaluation and analysis of online geocoding services. Int J Geographical Information Sci 2010, 24:1081-1100.

34. Simon PA, Kwan D, Angelescu A, Shih M, Fielding JE: Proximity of fast food restaurants to schools: do neighborhood income and type of school matter? Prev Med 2008, 47:284-288.

35. Zenk SN, Powell LM: US secondary schools and food outlets. Health Place 2008, 14:336-346.

36. Austin SB, Melly SJ, Sanchez BN, Patel A, Buka S, Gortmaker SL: Clustering of fast-food restaurants around schools: a novel application of spatial statistics to the study of food environments. Am J Public Health 2005, 95:1575-1581.

37. King G, Honaker J, Joseph A, Scheve K: Analyzing incomplete political science data: An alternative algorithm for multiple imputation. Am Polit Sci Rev 2001, 95:49-69.

38. Kestens $Y$, Daniel M: Social inequalities in food exposure around schools in an urban area. Am J Prev Med 2010, 39:33-40. 
39. Craypo L, Purcell A, Samuels SE, Agron P, Bell E, Takada E: Fast food sales on high school campuses: results from the 2000 California high school fast food survey. J Sch Health 2002, 72:78-82.

40. Wiecha JL, Finkelstein D, Troped PJ, Fragala M, Peterson KE: School vending machine use and fast-food restaurant use are associated with sugar-sweetened beverage intake in youth. J Am Diet Assoc 2006, 106:1624-1630

41. Spear BA, Barlow SE, Ervin C, Ludwig DS, Saelens BE, Schetzina KE, Taveras EM: Recommendations for treatment of child and adolescent overweight and obesity. Pediatrics 2007, 120(Suppl 4):S254-88.

42. Creel JS, Sharkey JR, McIntosh A, Anding J, Huber JCJ: Availability of healthier options in traditional and nontraditional rural fast-food outlets. BMC Public Health 2008, 8:395.

43. Rose D, Bodor JN, Hutchinson PL, Swalm CM: The importance of a multidimensional approach for studying the links between food access and consumption. J Nutr 2010, 140:1170-1174.

44. Subramanian SV, Jones K, Duncan C: Multilevel models for public health research. In Neighborhoods and Health. Edited by: Kawachi I, Berkman LF. New York: Oxford University Press; 2003:65-111.

\section{Pre-publication history}

The pre-publication history for this paper can be accessed here: http://www.biomedcentral.com/1471-2458/11/68/prepub

doi:10.1186/1471-2458-11-68

Cite this article as: Howard et al.: Proximity of food retailers to schools and rates of overweight ninth grade students: an ecological study in California. BMC Public Health 2011 11:68.

\section{Submit your next manuscript to BioMed Central} and take full advantage of:

- Convenient online submission

- Thorough peer review

- No space constraints or color figure charges

- Immediate publication on acceptance

- Inclusion in PubMed, CAS, Scopus and Google Scholar

- Research which is freely available for redistribution

Submit your manuscript at www.biomedcentral.com/submit
Biomed Central 